\title{
FAKTOR-FAKTOR YANG BERHUBUNGAN DENGAN TERJADINYA INFEKSI SALURAN PERNAPASAN AKUT (ISPA) PADA PEKERJA PANGLONG KAYU KABUPATEN ACEH JAYA TAHUN 2014
}

\author{
Cut Nelly Juwita ${ }^{1}$, Jun Musnadi Is ${ }^{2}$
}

Fakultas Kesehatan Masyarakat, Universitas Teuku Umar, Aceh Barat, Indonesia

\begin{abstract}
ABSTRAK
Penyakit infeksi masih banyak ditemukan di negara berkembang termasuk Indonesia. Salah satunya adalah Infeksi Saluran Pernafasan Akut (ISPA). Berdasarkan pengamatan kurangnya kesadaran pekerja panglong kayu terhadap kebersihkan lingkugan tempat kerja dan lamanya pekerja yang melakukan aktifitas dipanglong kayu yang dapat menyebabkan dampak yang sangat berbahaya pada pernapasan,debu kayu yang terus menerus masuk kedalan tubuh sehingga bisa menyebabkan terjadinya (ISPA). Penelitian ini merupakan penelitian survey yang bersifat analitik dengan desain Cross-Sectional yang bertujuan untuk melihat hubungan antara lingkungan kerja, Alat Pelindung Diri (Masker) dan lama bekerja dengan kejadian penyakit infeksi saluran pernapasan akut (ISPA). Populasi dalam penelitian ini adalah seluruh pekerja panglong kayu yang ada di Kabupaten Aceh Jaya berjumlah 30 orang. Sampel dalam penilitian ini adalah total populasi berjumlah 30 orang.

Hasil Penelitian menunjukkan ada hubungan antara lingkungan kerja dengan kejadian penyakit Infeksi Saluran Pernapasan Akut (ISPA) $\mathrm{P}_{\text {value }}(0,001)<\alpha(0,05)$. Tidak ada hubungan antara pemakaian masker dengan kejadian penyakit Infeksi Saluran Pernapasan Akut (ISPA) $\mathrm{P}_{\text {value }}(0,066)>\alpha(0,05)$. Ada hubungan antara lama bekerja dengan kejadian penyakit Infeksi Saluran Pernapasan Akut (ISPA) $\mathrm{P}_{\text {value }}(0,003)<\alpha$ $(0,05)$. Kesimpulan bahwa pekerja panglong kayu sangat rentang dengan kejadian penyakit ISPA karena Lamanya bekerja dan kurangnya kesadaran Masyarakat untuk membersihkan tempat bekerja setelah melakukan pemotongan Kayu sehingga terjadinya Infeksi Saluran Pernapasan Akut (ISPA).
\end{abstract}

Kata Kunci : Lingkungan Kerja, Pemakaian Masker, Lama Bekerja, Penyakit ISPA

Kebijakan pembangunan nasional dalam sektor kesehatan yang ingin dicapai melalui pembangunan kesehatan adalah meningkatkan kesadaran, kemauan dan kemampuan hidup sehat bagi setiap orang. Pembangunan kesehatan pada hakikatnya adalah suatu upaya menyelenggarakan kesehatan oleh bangsa Indonesia, untuk mencapai kemampuan hidup sehat bagi setiap penduduk sehingga. dapat mewujudkan derajat kesehatan yang optimal. Faktor ekstrinsik yang pertama adalah keadaan bahan 
yang diinhalasi (gas, debu, uap). Ukuran dan bentuk berpengaruh dalam proses penimbunan debu, demikian pula dengan kelarutan dan nilai higroskopisnya. Komponen yang berpengaruh antara lain kecenderungan untuk bereaksi dengan jaringan di sekitarnya, keasaman atau tingkat alkalinitas (dapat berupa silia dan sistem enzim).

Dampak paparan debu yang terus menerus dapat menurunkan faal paru berupa obstruktif. Akibat penumpukan debu yang tinggi di paru dapat menyebabkan kelainan dan kerusakan paru. Penyakit yang disebabkan oleh infeksi masih banyak berkecamuk dinegara berkembang termasuk Indonesia. Infeksi Saluran Pernafasan Akut (ISPA) adalah salah satu masalah kesehatan masyarakat

(Mirnawati, 2000).Dalam skala Internasional diperkirakan bahwa setiap tahun diseluruh negara berkembang terdapat 15 juta kematian. Dari jumlah ini 4 juta kematian atau 26,6\% disebabkan oleh penyakit Infeksi Saluran Pernapasan Akut (ISPA) (Profil Kesehatan Indonesia, 2012).

Di Indonesia penyakit Infeksi Saluran Pernafasan Akut merupakan penyakit yang sering terjadi pada balita. Karena kondisi tubuhnya yang masih rentan dikarenakan belum mempunyai kekebalan alamiah terhadap Infeksi Saluran Pernapasan Akut (ISPA) (Depkes RI, 2010). Di Propinsi Aceh, penyakit Infeksi Saluran Pernafasan Akut (ISPA) merupakan penyakit urutan pertama dari 10 penyakit terbesar yang ditemukan dipuskesmas. Dari seluruh penderita rawat jalan di Puskesmas dalam Provinsi Aceh pada tahun 2012 ditemukan penderita penyakit Infeksi Saluran Pernafasan Akut (ISPA) mencapai 37,341 kasus atau 74,4 \% dan sekitar 22,4\% diataranya meninggal dunia. (Profil Kesehatan Provinsi Aceh, 2012)

Berdasarkan data yang diperoleh dari Dinas Kesehatan Kabupaten Aceh Jaya tahun 2013, Jumlah penderita Infeksi Saluran Pernapasan Akut (ISPA) seluruhnya pada tahun tersebut adalah 699 kasus (Dinas Kesehatan Kabupaten Aceh Jaya 2013). 


\section{Metodologi Penelitian}

Penelitian ini merupakan penelitian survey yang bersifat analitik dengan desain Cross-Sectional, dimana penulis ingin mengetahui faktor-faktor yang berhubungan denganterjadinya Infeksi Saluran Pernapasan Akut (ISPA) pada pekerja panglong kayudi Kabupaten Aceh Jaya Tahun 2014 (Notoatmodjo, 2005). Penelitian ini telah dilakukan di Panglong kayu di Kabupaten Aceh Jaya sebanyak 4 buah panglong kayu. Penelitian ini telah dilaksanakan pada bulan November 2014.

Populasi dalam penelitian ini adalah semua pekerja yang ada di Panglong Kayu di Kabupaten Aceh Jaya Tahun 2014 yaitu sebanyak 30 pekerja. Pengambilan sampel dalam penelitian ini adalah totalpopulasi yaitu semua populasi dijadikan sebagai sampel yaitu sebanyak 30 orang. Penelitian ini menggunakan data primer dengan cara observasi dan wawancara dengan menggunakan cheklist dan kuesioner untuk pekerja panglong kayu dan Data sekunder didapatkan di Dinas Kesehatan Kabupaten Aceh Jaya, Dinas Kesehatan Provinsi Aceh, serta literatur-literatur lainnya yang berhubungan dengan permasalahan penelitian ini.

\section{Hasil dan Pembahasan}

\section{Hasil}

Kabupaten Aceh Jaya secara geografis terletak pada 0422' -0516' Lintang Utara 9502-9603 Bujur Timur dengan luas daerah 3.727 Km. batas wilayah Aceh Jaya terbagi dalam 9 Kecamatan, 22 Mukim dan 173 Desa. Jumlah Pekerja Panglong Kayu diwilayah Kabupaten Aceh Jaya pada saat ini berjumlah 30orang yang semuanya lakilaki. Pendidikan para pekerja Panglong Kayu tamatan SMA. 
Table 1. Distribusi Frekwensi Data Umur dengan Kejadian Penyakit Infeksi Saluran Pernapasan Akut (ISPA) Pada Pekerja di Panglong Kayu Kabupaten Aceh Jaya Tahun 2014.

\begin{tabular}{cccc}
\hline No & Umur & Frekuensi & \% \\
\hline 1 & 30 s/d 35 tahun & 10 & 33,33 \\
2 & 36s/d 50 tahun & 20 & 66,67 \\
\hline Total & $\mathbf{3 0}$ & $\mathbf{1 0 0}$
\end{tabular}

Sumber : Data Primer Diolah 2014

Berdasarkan tabel 4.1 dapat dilihat bahwa 30 orang pekerja yang umur $36 \mathrm{~s} / \mathrm{d}$ 50 tahun sebanyak 20 orang $(66,67 \%)$ dan umur 30 s/d 35 tahun sebanyak 10 orang $(33,33 \%)$.

Table 2. Distribusi Frekwensi Data Jenis Kelamin dengan Kejadian Penyakit Infeksi Saluran Pernapasan Akut (ISPA) Pada Pekerja di Panglong Kayu Kabupaten Aceh Jaya Tahun 2014.

\begin{tabular}{cccc}
\hline No & Jenis Kelamin & Frekuensi & \% \\
\hline 1 & Laki-laki & 30 & 100 \\
\hline \multicolumn{2}{c}{ Total } & $\mathbf{3 0}$ & $\mathbf{1 0 0}$
\end{tabular}

Sumber : Data Primer Diolah 2014

Berdasarkan tabel 4.2 dapat dilihat bahwa 30 orang pekerja semuanya laki-laki $(100 \%)$.

Table 3. Distribusi Frekwensi Data Pendidikan dengan Kejadian Penyakit Infeksi Saluran Pernapasan Akut (ISPA) Pada Pekerja di Panglong Kayu Kabupaten Aceh Jaya Tahun 2014.

\begin{tabular}{|c|c|c|c|}
\hline No & Pendidikan & Frekuensi & $\%$ \\
\hline 1 & SD & 0 & 0 \\
\hline 2 & SMP/MTsN & 8 & 26,67 \\
\hline 3 & SMA & 22 & 73,33 \\
\hline 4 & Diploma & 0 & 0 \\
\hline 5 & Perguruan Tinggi & 0 & 0 \\
\hline & Total & 30 & 100 \\
\hline
\end{tabular}

Sumber : Data Primer Diolah 2014

Berdasarkan tabel 4.3 dapat dilihat bahwa 30 orang pekerja yang SMP sebanyak 8 orang $(26,67 \%)$, dan SMA sebanyak 22 orang $(73,33 \%)$.

Table 4. Distribusi Frekwensi Data Lingkungan Kerja dengan Kejadian Penyakit Infeksi Saluran Pernapasan Akut (ISPA) Pada Pekerja di Panglong Kayu Kabupaten Aceh Jaya Tahun 2014.

\begin{tabular}{cccc}
\hline No & Lingkungan Kerja & Frekuensi & \% \\
\hline 1 & Mendukung & 13 & 43,3 \\
2 & Tidak Mendukung & 17 & 56,7 \\
\hline \multicolumn{2}{c}{ Total } & $\mathbf{3 0}$ & $\mathbf{1 0 0}$
\end{tabular}


Sumber : Data Primer Diolah 2014

Berdasarkan tabel 4.4 dapat dilihat bahwa 30 orang pekerja yang lingkungan kerja tidak mendukung sebanyak 17 orang $(56,7 \%)$ dan lingkungan kerjamendukung sebanyak 13 orang $(43,3 \%)$.

Table 5. Distribusi Frekwensi Data Pemakaian Alat Pelindung Diri (Masker) dengan Ke jadian Penyakit Infeksi Saluran Pernapasan Akut (ISPA) Pada Pekerja di Panglong Kayu Kabupaten Aceh Jaya Tahun 2014.

\begin{tabular}{clcc}
\hline No & Pemakaian Alat Pelindung Diri (Masker) & Frekuensi & \% \\
\hline 1 & Digunakan & 15 & 50 \\
2 & Tidak Digunakan & 15 & 50 \\
\hline \multicolumn{2}{r}{ Total } & $\mathbf{3 0}$ & $\mathbf{1 0 0}$ \\
\hline
\end{tabular}

Sumber : Data Primer Diolah 2014

Berdasarkan tabel 4.5 dapat dilihat bahwa 30 orang pekerja yang Pemakaian Maskertidak digunakan sebanyak 15 orang (50\%), dan yang pemakaian Masker digunakan sebanyak 15 orang( $50 \%)$.

Table 6. Distribusi Frekwensi DataLamanya Bekerja dengan Kejadian Penyakit Infeksi Saluran Pernapasan Akut (ISPA) Pada Pekerja di Panglong Kayu Kabupaten Aceh Jaya Tahun 2014.

\begin{tabular}{|c|c|c|c|}
\hline No & Lamanya Bekerja & Frekuensi & $\%$ \\
\hline 1 & Lama & 14 & 46,7 \\
\hline 2 & Baru & 16 & 53,3 \\
\hline & Total & 30 & 100 \\
\hline
\end{tabular}

Sumber : Data Primer Diolah 2014

Berdasarkan tabel 4.6 dapat dilihat bahwa 30 orang pekerja lamanya bekerja baru sebanyak 16 responden (53,3\%), dan lamanya bekerja lamasebanyak 14 responden $(46,7 \%)$.

Table 7. Distribusi Frek wensi Data Kejadian Penyakit Infeksi Saluran Pernapasan Akut (ISPA) Pada Pekerja di Panglong Kayu Kabupaten Aceh Jaya Tahun 2014.

\begin{tabular}{clcc}
\hline No & Kejadian Penyakit ISPA & Frekuensi & \% \\
\hline 1 & Terpapar & 14 & 46,7 \\
2 & Tidak Terpapar & 16 & 53,3 \\
\hline \multicolumn{2}{c}{ Total } & $\mathbf{3 0}$ & $\mathbf{1 0 0}$ \\
\hline
\end{tabular}

Sumber : Data Primer Diolah 2014

Berdasarkan tabel 4.7 dapat dilihat bahwa 30 orang pekerja yang kejadian penyakit Infeksi Saluran Pernapasan Akut (ISPA) tidak terpapar sebanyak 16 responden 
$(53,3 \%)$, dan kejadian penyakit Infeksi Saluran Pernapasan Akut (ISPA) terpapar sebanyak 14 responden $(46,7 \%)$.

1. Hubungan Antara Lingkungan Kerja Dengan Kejadian Penyakit Infeksi Saluran Pernapasan Akut (ISPA)

Table 8. Distribusi Frekwensi Data Lingkungan Kerja denganKejadian Penyakit Infeksi Saluran Pe mapasan Akut (ISPA) Pada Pekerja di Panglong Kayu Kabupaten Aceh Jaya Tahun 2014.

\begin{tabular}{|c|c|c|c|c|c|c|c|c|c|}
\hline \multirow{3}{*}{ No } & \multirow{3}{*}{$\begin{array}{c}\text { Lingkungan } \\
\text { Kerja }\end{array}$} & \multicolumn{4}{|c|}{ Kejadian Penyakit ISPA } & \multirow{2}{*}{\multicolumn{2}{|c|}{ Total }} & \multirow{3}{*}{$\boldsymbol{P}$} & \multirow{3}{*}{$\alpha$} \\
\hline & & \multicolumn{2}{|c|}{ Terpapar } & \multicolumn{2}{|c|}{$\begin{array}{c}\text { Tidak } \\
\text { Terpapar }\end{array}$} & & & & \\
\hline & & Frek & $\%$ & Frek & $\%$ & Frek & $\%$ & & \\
\hline 1 & Mendukung & 11 & 84,61 & 2 & 15,38 & 13 & 100 & \multirow{2}{*}{0,001} & \multirow{2}{*}{0,05} \\
\hline 2 & Tidak Mendukung & 3 & 17,64 & 14 & 82,35 & 17 & 100 & & \\
\hline & Total & 14 & 46,7 & 16 & 53,3 & 30 & 100 & & \\
\hline
\end{tabular}

Sumber : Data Primer diolah 2014

Dari hasil table 4.8 sebanyak 30 responden diketahui bahwa sebanyak 13 responden lingkungan kerja mendukung terpapar sebanyak 11 responden $(84,61 \%)$, lingkungan kerja mendukung tidak terpapar sebanyak 2 responden $(15,38 \%)$ dan 17 responden lingkungan kerja tidak mendukung terpapar sebanyak 3 responden $(17,64 \%)$, lingkungan kerja tidak mendukung tidak terpapar sebanyak 14 responden $(82,35 \%)$ sedangkanbeda proporsi dengan chi-square diperoleh nilai $\alpha(0,05)$, sedangkan nilai $\mathrm{P}_{\text {value }}(0,01)$ atau $\mathrm{P}_{\text {value }}(0,001)<\alpha(0,05)$ berarti dapat dipustuskan Ho ditolak, dan dapat disimpulkan ada hubungan lingkungan kerja dengan kejadian penyakit Infeksi Saluran Pernapasan Akut (ISPA). Hitungan chi-square dapat dilihat pada lampiran. 
2. Hubungan Antara Pemakaian Alat Pelindung Diri (Masker) Dengan Kejadian Penyakit Infeksi Saluran Pemapasan Akut (ISPA).

Tabel 9. Distribusi Frekwensi Data Pemakaian Masker dengan Kejadian Penyakit Infeksi Saluran Pernapasan Akut (ISPA) Pada Pekerja di Panglong Kayu Kabupaten Aceh Jaya Tahun 2014.

\begin{tabular}{|c|c|c|c|c|c|c|c|c|c|}
\hline \multirow{3}{*}{ No } & \multirow{3}{*}{$\begin{array}{c}\text { Pemakaian } \\
\text { Alat } \\
\text { Pelindung } \\
\text { Diri } \\
\text { (Masker) }\end{array}$} & \multicolumn{4}{|c|}{ Kejadian Penyakit ISPA } & \multirow{2}{*}{\multicolumn{2}{|c|}{ Total }} & \multirow{3}{*}{$\boldsymbol{P}$} & \multirow{3}{*}{$\alpha$} \\
\hline & & \multicolumn{2}{|c|}{ Terpapar } & \multicolumn{2}{|c|}{$\begin{array}{c}\text { Tidak } \\
\text { Terpapar }\end{array}$} & & & & \\
\hline & & $\begin{array}{c}\text { Fre } \\
\mathbf{k}\end{array}$ & $\%$ & Frek & $\%$ & Frek & $\%$ & & \\
\hline 1 & Digunakan & 10 & 66,66 & 5 & 33,33 & 15 & 100 & & \\
\hline 2 & $\begin{array}{l}\text { Tidak } \\
\text { Digunakan }\end{array}$ & 4 & 26,66 & 11 & 73,33 & 15 & 100 & $\begin{array}{c}0,06 \\
6\end{array}$ & 0,05 \\
\hline & Total & 14 & 46,7 & 16 & 53,33 & 30 & 100 & & \\
\hline
\end{tabular}

Sumber : Data Primer diolah 2014

Dari table 4.9 sebanyak 30 responden diketahui bahwa sebanyak 15 responden pemakaian alat pelindung diri (masker) digunakan terpapar sebanyak 10 responden $(66,66 \%)$, pemakaian alat pelindung diri (masker) digunakan tidak terpapar sebanyak 5 responden $(33,33 \%)$ dan 15 responden pemakaian alat pelindung diri (masker) tidak digunakan terpapar sebanyak 4 responden $(26,66 \%)$, pemakaian alat pelindung diri (masker) tidak digunakan tidak terpapar sebanyak 11 responden $(73,33 \%)$ sedangkan hasil beda proporsi dengan chi-square diperoleh nilai $\alpha(0,05)$, sedangkan nilai $\mathrm{P}_{\mathrm{value}}$ $(0,066)$ atau $\mathrm{P}_{\text {value }}(0,066)>\alpha(0,05)$ berarti dapat dipustuskan Ho diterima, dan dapat disimpulkantidak ada hubungan pemakaian alat pelindung diri (masker) dengan kejadian penyakit ISPA. Hitungan chi-square dapat dilihat pada lampiran.

3. Hubungan Antara Lamanya Kerja Dengan Ke jadian Penyakit Infeksi Saluran Pernapasan Akut (ISPA).

Tabel 10. Distribusi Frekwensi Data Lamanya Kerja dengan Kejadian Penyakit Infeksi Saluran Pernapasan Akut (ISPA) Pada Pekerja di Panglong Kayu Kabupaten Aceh Jaya Tahun 2014.

\begin{tabular}{|c|c|c|c|c|c|c|c|c|c|}
\hline \multirow{3}{*}{ No } & \multirow{3}{*}{$\begin{array}{c}\text { Lama } \\
\text { Bekerja }\end{array}$} & \multicolumn{4}{|c|}{ Kejadian Penyakit ISPA } & \multirow{2}{*}{\multicolumn{2}{|c|}{ Total }} & \multirow{3}{*}{$\boldsymbol{P}$} & \multirow{3}{*}{$\alpha$} \\
\hline & & \multicolumn{2}{|c|}{ Terpapar } & \multicolumn{2}{|c|}{$\begin{array}{c}\text { Tidak } \\
\text { Terpapar } \\
\end{array}$} & & & & \\
\hline & & Frek & $\%$ & Frek & $\%$ & Frek & $\%$ & & \\
\hline 1 & Lama & 11 & 78,57 & 3 & 21,42 & 14 & 100 & \multirow{2}{*}{0,003} & \multirow{2}{*}{0,05} \\
\hline 2 & Baru & 3 & 18,75 & 13 & 81,25 & 16 & 100 & & \\
\hline & Total & 14 & 46,7 & 16 & 53,3 & 30 & 100 & & \\
\hline
\end{tabular}


Dari hasil tabel 4.10 sebanyak 30 responden diketahui bahwa sebanyak 14 responden lama bekerja lama terpapar sebanyak 11 responden $(78,57 \%)$, lama bekerja lama tidak terpapar sebanyak 3 responden $(21,42 \%)$ dan 16 responden lama bekerja baru terpapar sebanyak 3 responden $(18,75 \%)$, lama bekerja baru tidak terpapar sebanyak 13 responden $(81,25 \%)$ sedangkan beda proporsi dengan chi-square diperoleh nilai $\alpha(0,05)$, sedangkan nilai $\mathrm{P}_{\text {value }}(0,003)$ atau $\mathrm{P}_{\text {value }}(0,003)<\alpha(0,05)$ berarti dapat dipustuskan Ho ditolak, dan dapat disimpulkan ada hubungan lama bekerja dengan kejadian penyakit ISPA. Hitungan chi-square dapat dilihat pada lampiran.

\section{Pembahasan}

\section{Lingkungan Kerja dengan Kejadian Penyakit Infeksi Saluran Pernapasan Akut (ISPA)}

proporsi dengan chi-square diperoleh nilai $\alpha(0,05)$, sedangkan nilai $\mathrm{P}_{\mathrm{value}}(0,01)$ atau $\mathrm{P}_{\text {value }}(0,001)<\alpha(0,05)$ berarti dapat dipustuskan Ho ditolak, dan dapat disimpulkan ada hubungan lingkungan kerja dengan kejadian penyakit Infeksi Saluran Pernapasan Akut (ISPA).

Lingkungan kerja sangat mempengaruhi terjadinya penyakit Infeksi Saluran Pernapasan Akut (ISPA). karena penyebab penyakit Infeksi Saluran Pernapasan Akut (ISPA). terjadi merupakan faktor debu yang berterbangan pada waktu mengetam kayu, menggergaji kayu dan pada waktu membelah kayu sehingga debu yang sangat kecil terhidup dan masuk kehidung melalui pernapasan sehingga terjadilah penyakit Infeksi Saluran Pernapasan Akut (ISPA).

Sebuah lingkungan kerja yang dapat diidentifikasi sebagai tempat yang satu bekerja. yaitu-dalam sebuah gedung perkantoran di kubus, di rumah di meja dapur, dari mobil atau truk, di lokasi konstruksi. Semua lingkungan kerja. Kita cenderung, namun, untuk mendengar tentang "lingkungan kerja yang sehat." Hal ini dapat menunjukkan faktor-faktor lain di lingkungan kerja, seperti rekan kerja, kualitas udara, tempat duduk ergonomis, manajemen. Lingkungan kerja yang tidak memerlukan pekerjaan. Hal ini membutuhkan pekerjaan yang harus dilakukan di beberapa tempat.

Lingkungan Kerja didesain sedemikian rupa agar dapat tercipta hubungan kerja yang memikat pekerja dengan lingkungannya. Lingkungan kerja yang baik yaitu apabila 
karyawan dapat melakukan kegiatan secara optimal, sehat, aman dan nyaman. Lingkungan kerja yang kurang baik dapat menuntut tenaga kerja serta waktu yang lebih banyak dan tidak mendukung diperolehnya rencangan system kerja yang efisien (Subowo, 2005).

\section{Pemakaian Alat Pelindung Diri (Masker) dengan Kejadian Penyakit Infeksi Saluran Pernapasan Akut (ISPA)}

Proporsi dengan chi-square diperoleh nilai $\alpha(0,05)$, sedangkan nilai $\mathrm{P}_{\text {value }}$ $(0,066)$ atau $\mathrm{P}_{\text {value }}(0,066)>\alpha(0,05)$ berarti dapat dipustuskan Ho diterima, dan dapat disimpulkantidak ada hubungan pemakaian Alat Pelindung Diri (Masker) dengan kejadian penyakit ISPA.

Pemakaian masker pada waktu melakukan pekerjaan di panglong kayu sangatlah baik untuk menghindari bahaya debu dalam waktu yang lama, karena pemakaian masker untuk menghindari penyakit Infeksi Saluran Pernapasan Akut (ISPA). Bukan pada waktu sekarang melainkan waktu yang lama. Sebab efek dari debu hasil mengetam, memotong kayu di pangglong bukan tidak timbul langsung melainkan waktu yang lama baru akan timbul penyakit.

Menurut pendapat (Suma'mur P.K, 2001). Jadi alat pelindung diri adalah merupakan salah satu cara untuk mencegah kecelakaan, dan secara teknis masker tidaklah sempurna dapat melindungi tubuh akan tetapi dapat mengurangi tingkat keparahan dari kecelakaan yang terjadi.

Peralatan pelindung tidak menghilangkan ataupun mengurangi bahaya yang ada. Peralatan ini hanya mengurangi jumlah kontak dengan bahaya dengan cara penempatan penghalang antara tenaga kerja dengan bahaya. Banyak faktor yang dapat mengurangi efektivitas dari peralatan pelindung. Efektivitas sistem ini juga sangat bergantung pada perilaku tenaga kerja. Tanpa peralatan yang tepat, pelatihan yang memadai, penyimpanan dan perawatan yang baik, aplikasi peralatan pelindung tenaga keija tidak akan efektif dalam mengendalikan (Suma'mur P.K, 2001).

Menurut Yusnabeti, Ririn Arminsih Wulandari, Rut Lucia tahun 2010, dari 43 pekerja mebel yang mengalami ISPA, hampir semua pekerja tidak menggunakan APD, seperti masker atu penutup hidung yang lain. Berdasarkan hasil pengamatan dan wawancara, pengguna masker selama kerja dapat menggangu kenyamanan pekerja. 
Pekerja di lokasi penelitian hanya menggunakan masker jika kayu yang diolah berupa kayu kering oven karena debu dari kayu tersebut lebih tajam mempenyaruhi mata dan pernapasan.

\section{Lama Bekerja dengan Kejadian Penyakit Infeksi Saluran Pernapasan Akut (ISPA)}

Proporsi dengan chi-square diperoleh nilai $\alpha(0,05)$, sedangkan nilai $\mathrm{P}_{\text {value }}$ $(0,003)$ atau $\mathrm{P}_{\text {value }}(0,003)<\alpha(0,05)$ berarti dapat dipustuskan Ho ditolak, dan dapat disimpulkan ada hubungan lama bekerja dengan kejadian penyakit Infeksi Saluran Pernapasan Akut (ISPA).

Pekerja yang sudah lama bekerja dipanglong kayu sangat memungkinkan terjadinya penyakit Infeksi Saluran Pernapasan Akut (ISPA).karena debu yang masuk kedalam hidung melalui pernapasan sudah sangat banyak sehingga menimbulkan penyakit Infeksi Saluran Pernapasan Akut (ISPA).

Waktu kerja adalah sebuah kuantitas yang dapat diukur untuk individu atau, secara agregat, untuk masyarakat. Dalam kasus terakhir, pekan kerja 40 jam akan berarti bahwa mempekerjakan individu-individu dalam masyarakat, rata-rata, bekerja 40 jam per minggu. Beberapa negara-negara industri secara hukum mandat panjang seminggu bekerja maksimal antara 35 dan 45 jam per minggu dan memerlukan 2 sampai 5 minggu per tahun liburan. Namun, sebenarnya jam kerja per minggu tidak dapat jatuh di bawah minimum tertentu tanpa mengorbankan kemampuan bangsa untuk menghasilkan standar materi hidup warganya terbiasa. Jika minggu kerja terlalu pendek dibandingkan dengan yang ideal bahwa masyarakat, maka masyarakat menderita setengah pengangguran tenaga kerja dan modal manusia. Semua sederajat, ini akan cenderung menghasilkan pendapatan riil yang lebih rendah dan standar hidup yang lebih rendah daripada apa yang bisa memiliki satu minggu bekerja lebih lama dalam masyarakat yang sama. Sebaliknya, seminggu kerja yang terlalu panjang akan menghasilkan menghasilkan lebih banyak uang pada biaya stres masalah kesehatan terkait serta "kekeringan waktu luang." Selanjutnya, anak-anak cenderung kurang mendapat perhatian dari orang tua sibuk, dan membesarkan anak mungkin subyektif buruk. Cara yang tepat yang mempengaruhi jam kerja dalam seminggu selama budaya, kesehatan masyarakat, dan pendidikan yang diperdebatkan. 
Menurut Yusnabeti, Ririn Arminsih Wulandari, Rut Lucia tahun 2010, hubungan masa kerja dengan ISPA. Masa kerja berhubungan dengan ISPA. Pekerja yang bekerja $\geq 10$ tahun lebih beresiko terkena ISPA dibandingkan dengan pekerja yang bekerja $<10$ tahun. Masa kerja dapat meningkatkan lamanya pekerja terpanjang dengan PM10. Dari hasil penelirian didapatkan rata-rata waktu kerja selama 9-0 jam/hari selama 7 hari dalam satu minggu. Lama bekerja umumnya 6-8 jam/hari dan 40 jam dalam satu minggu atau 5-6 hari dalam satu minggu.

\section{Kesimpulan}

Nilai $\alpha(0,05)$, sedangkan nilai $\mathrm{P}_{\text {value }}(0,01)$ atau $\mathrm{P}_{\text {value }}(0,001)<\alpha(0,05)$ berarti dapat dipustuskan Ho ditolak, dan dapat disimpulkan ada hubungan lingkungan kerja dengan kejadian penyakit Infeksi Saluran Pernapasan Akut (ISPA). Nilai $\alpha(0,05)$, sedangkan nilai $\mathrm{P}_{\text {value }}(0,066)$ atau $\mathrm{P}_{\text {value }}(0,066)>\alpha(0,05)$ berarti dapat dipustuskan Ho diterima, dan dapat disimpulkan tidak ada hubungan pemakaian Alat Pelindung Diri (Masker) dengan kejadian penyakit Infeksi Saluran Pernapasan Akut (ISPA). Nilai $\alpha$ $(0,05)$, sedangkan nilai $\mathrm{P}_{\text {value }}(0,003)$ atau $\mathrm{P}_{\text {value }}(0,003)<\alpha(0,05)$ berarti dapat dipustuskan Ho ditolak, dan dapat disimpulkan ada hubungan lama bekerja dengan kejadian penyakit Infeksi Saluran Pernapasan Akut (ISPA.

\section{Daftar Pustaka}

Budiono, 2003, Kesehatan Kerja, Jakarta.

Depkes, RI, 2010. Manajemen Terpadu Balita Sakit (MTBS). Kerja Sama dengan WHO dan UNICEF, Jakarta.

Depkes, RI, 2002. ISPA Harus Dicegah Sekarang Juga. Jakarta.

Depkes, RI, 2004. Basmi Penyakit Menular. Jakarta.

Depkes, RI, 2010. Pembangunan Kesehatan Nasional. Jakarta.

Depkes, RI, 2012. Profil Kesehatan Indonesia. Jakarta.

Dinkes, DKI Jakarta 2002, Jurnal Kesehatan. Jakarta. 
Dinkes, Aceh, 2012. Profil Kesehatan Aceh, Banda Aceh.

Dinkes, Aceh Jaya, 2014. Profil Kesehatan Kesehatan Aceh Jaya, Calang.

Etjang, 2005. Pencegahan Penyakit Infeksi Saluran Pernapasan Akut (ISPA) Jakarta.

FKM Universitas Teuku Umur, 2014. Pedoman Penulisan Skripsi, Meulaboh.

Habsari, 2003. Penggunaan APD bagi Tenaga Kerja. Bunga Rampai Hiperkes dan

Keselamatan Kerja, UNDIP, Semarang.

Mirnawati, 2000. Kesehatan Indonesia Masa Depan. Jakarta.

Notoatmojo, 2005. Metodelogi Penelitian Kesehatan. PT. Rineka Cipta. Jakarta.

Rahmatullah. P, 2006. Penyakit Paru Lingkungan - Kerja.Bagian Penyakit Dalam FK UNDIP, Semarang.

Suma'mur. PK, 2001, Higiene Perusahaan Dan Kesehatan Kerja, CV. Hajimasagung, Jakarta.

Subowo. 2005. Kesehatan Kerja, Jakarta, 2005.

Tjokrokusumo K.R.T, 2005. Pengantar Enjiniring Lingkungan. STTL "YLH", Penerbit ANDI, Yogyakarta.

Wardhana. A.W, 2001. Dampak Pencemaran Lingkungan. ANDI,Yogyakarta.

Warta Posyandu, 2006.ISPA dan Pneumonia Pembunuh Utama bayi di Indonesia, Jakarta.

Word Health Organisasion (WHO). 2002, Penyakit Infeksi Saluran Pernapasan Akut (ISPA). Jakarta 